Relations industrielles

Industrial Relations

\title{
Les doctrines économiques, par A. Hamelin. Collection « Vous connaîtrez ». Les Editions ouvrières, 12, avenue Soeur-Rosalie, Paris, 13. 1959, 186 pages.
}

\section{Gérard Dion}

Volume 14, numéro 3, juillet 1959

URI : https://id.erudit.org/iderudit/1022302ar

DOI : https://doi.org/10.7202/1022302ar

Aller au sommaire du numéro

Éditeur(s)

Département des relations industrielles de l’Université Laval

ISSN

0034-379X (imprimé)

1703-8138 (numérique)

Découvrir la revue

Citer ce compte rendu

Dion, G. (1959). Compte rendu de [Les doctrines économiques, par A. Hamelin. Collection « Vous connaîtrez ». Les Editions ouvrières, 12, avenue

Soeur-Rosalie, Paris, 13. 1959, 186 pages.] Relations industrielles / Industrial

Relations, 14(3), 444-444. https://doi.org/10.7202/1022302ar

Tous droits réservés @ C Département des relations industrielles de l’Université Laval, 1959
Ce document est protégé par la loi sur le droit d'auteur. L'utilisation des services d’Érudit (y compris la reproduction) est assujettie à sa politique d'utilisation que vous pouvez consulter en ligne.

https://apropos.erudit.org/fr/usagers/politique-dutilisation/ 
des salaires dans l'hypothèse du plein emploi.

Plus de la moitié de l'étude de Sturmthal porte sur les salaires; le reste a pour objet la négociation. Au début l'auteur signale la difficulté de comparer le degré d'importance de la négociation d'un pays à l'autre. Lorsqu'il traite de la centralisation des négociations et de l'uniformisation conséquente des conditions de travail, Sturmthal est très intéressant, mais il excelle quand il analyse le problème de l'extention légale des conventions et il ne manque pas alors de scruter avec beaucoup de pénétration la psychologie patronale et ouvrière afin d'expliquer les causes et les effets de ce phénomène.

Dans la partie qui se rapporte aux salaires, Sturmthal commence par comparer les différences entre les taux des ouvriers qualifiés et ceux des travailleurs qui ne le sont pas. Il constate que la différence de niveau entre ces deux catégories est beaucoup plus restreinte en Europe qu'aux Etats-Unis. Il fait sur ce point l'inventaire de plusieurs hypothèses mais ne trouve pas d'explication satisfaisante. Il ne consacre même pas une page entière par la suite aux différences entre les branches d'activité écoromique, entre les salaires des hommes et des femmes, et à peine plus aux différences régionales.

L'auteur s'arrête brièvement au problème d'une structure «rationnelle 》 des salaires, et signale que là où de sérieux efforts ont été accomplis dans cette direction, la réalité ne s'est pas laissée plier aux cadres rigides qu'on a cherché à lui imposer. Il traite assez longuement de la négociation collective et des niveaux de salaires. La négociation a tendance à uniformiser les salaires, mais le niveau qui sert de barême n'est pas le même dans tous les régimes: aux Etats-Unis, par le truchement des négociations-clés (pattern bargaining ) les salaires ont tendance à s'aligner au niveau de ceux des branches d'activité et des entreprises les plus prospères; en Europe, au contraire, ils sont liés au niveau de la capacité de payer des entreprises marginales. Cette méthode européenne réduit la concurrence et facilite la transformation de l'augmentation des salaires en des majorations de prix dans tout le marché.

Sturmthal termine son essai par des réflexions sur le problème de la stab1- lité des prix dans une économie de plein emploi. Il conclut en affirmant qu'il n'existe aucune méthode qui soit également efficace d'un pays à l'autre dans la recherche de cet équilibre.

\section{Gaston Cholette}

Les doctrines économiques, par A. Hamelin. Collection «Vous connaîtrez 》. Les Editions ouvrières, 12, avenue Soeur-Rosalie, Paris, 13. 1959, 186 pages.

L'auteur présente une synthèse des différentes doctrines économiques préconisées à travers les âges. Il s'attache particulièrement au mercantilisme, aux physiocrates, à l'école libérale ou classique, au socialisme et aux écoles nonsocialisies. Enfin, il dit un mot de la réaction contre la science classique: doctrines historique et hédoniste. Malheureusement, il ne s'étend pas assez sur les doctrines de l'époque contemporaine, celles qui nous touchent plus profondément. C'est un ouvrage de vulgarisation pour les gens pressés qui n'ont pas le temps d'étudier à fond les ouvrages spécialisés. Cependant nous craignons qu'en raison de la lacune signalée, ils n'y trouvent pas tout $\infty$ qu'ils attendent.

GÉrard Dion

Forces et faiblesses des entreprises familiales. Centre d'études des problèmes industriels. Edition «Pilote 》, 109, rue de la Bassée, Lille, 1959, 157 pp.

La plupart des études en relations du travail portent sur les entreprises de grandes dimensions, organisées en corporations et dirigées par un bureau de direction représentant juridiquement des actionnaires anonymes. S'il est vrai que notre économie est marquée par ce genre d'entreprises à cause de leur importance économique et de la quantité de main-d'oeuvre qu'elles emploient, il est incontestable qu'au Canada, comme aux Etats-Unis et dans la plupart des pays d'Europe occidentale, la forme familiale de l'entreprise est encore celle qui est la plus répandue. Et le phénomène de concentration industrielle ne la fera pas disparaître, loin de là; elle aura toujours sa place parce qu'elle exerce une 